\title{
Association Between Recent Experience of Childbirth and Sleep Quality in South Korean Women: Results from a Nationwide Study
}

This article was published in the following Dove Press journal: Nature and Science of Sleep

\author{
Woorim Kim ${ }^{1} *$ \\ Yeong Jun Ju (D) $2,3, *$ \\ Soon Young Lee ${ }^{3}$ \\ 'Division of Cancer Control \& Policy, \\ National Cancer Control Institute, \\ National Cancer Center, Goyang-si, \\ Gyeonggi-do, Republic of Korea; \\ ${ }^{2}$ Institute of Health Services Research, \\ Yonsei University College of Medicine, \\ Seoul, Republic of Korea; ${ }^{3}$ Department of \\ Preventive Medicine and Public Health, \\ Ajou University School of Medicine, \\ Suwon-si, Gyeonggi-do, Republic of \\ Korea
}

*These authors contributed equally to this work
Correspondence: Soon Young Lee Department of Preventive Medicine and Public Health, Ajou University School of Medicine 206 World Cup-ro, Yeongtong-gu, Suwon-si, Gyeonggi-do, 16499, Republic of Korea

Tel +82-3|-2|9-530|

$\mathrm{Fax}+82-31-219-5084$

Email solee@aumc.ac.kr
Introduction: Although women commonly report deterioration of sleep quality postpartum, this relationship has been less studied in East Asian countries. This study investigated the association between recent experience of childbirth and sleep quality in South Korean women and additionally examined how healthy practice behavior interplays in the stated relationship.

Methods: Data from the 2018 Community Health Survey were used. Sleep quality was measured using the Pittsburgh sleep quality index (PSQI). Women who responded to have given birth in the past year were categorized as having a recent experience of childbirth. The general characteristics of the study population were investigated using chi-square test. The association between the dependent and independent variables was analyzed using multivariate logistic regression analysis.

Results: Of a total of 41,708 study participants, 16,877 (40.5\%) individuals reported poor sleep quality. Poor sleep quality was more common in women with a recent experience of childbirth $(48.4 \%)$ than those without $(40.0 \%)$. Compared to individuals without a recent experience of childbirth, those with such an experience were more likely to show poor sleep quality (OR 1.50, 95\% CI 1.34-1.68). Such differences were reduced in individuals with a healthy lifestyle.

Conclusion: Recent experience of childbirth was associated with higher likelihoods of poor sleep quality in women. The degree of risks found was reduced in individuals practicing a healthy lifestyle habit. The findings infer the need to monitor and address sleep-related disturbances commonly reported among postpartum women.

Keywords: sleep quality, sleep disturbances, postpartum, childbirth experience, healthy practice behavior

\section{Introduction}

Quality of sleep can be defined as the physiologic characteristics that produce a feeling of restoration. ${ }^{1}$ Sleep is known to have noticeable recuperative effects and has been reported as an essential function for memory consolidation. ${ }^{2}$ Better sleep is also known to improve cognitive performance, with poor sleep quality being related to subjective cognitive decline or subjective cognitive decline-related functional difficulties. ${ }^{3}$ Despite the importance of sleep quality on well-being and psychological functioning in humans, sleep quality is difficult to define or measure objectively due to its complex and subjective nature. ${ }^{4}$ In fact, psychological factors such as depression and anxiety are known to affect subjective feelings about sleep 
quality. Under such circumstances, the Pittsburgh sleep quality index (PSQI) is one scale commonly utilized to measure sleep quality in a more reliable and standardized manner. ${ }^{5}$ Specifically, the PSQI evaluates diverse aspects of sleep quality, including symptoms of insomnia and depression, over the course of one month. ${ }^{6}$

Identifying factors associated with sleep quality is particularly needed in the Asian population because profound reductions in sleep have been reported from these countries in the modern era. ${ }^{7}$ Experiences of giving childbirth have been identified as a noticeable risk factor, with many women commonly reporting increased experiences of sleep disturbances postpartum. ${ }^{8}$ The higher prevalence of poor sleep quality in postpartum women requires attention because fragmented, poor quality sleep is not only known to lead to increased neurobehavioral performance deficits, but also because the postpartum period is a markedly stressful and sensitive period for mothers in general. ${ }^{9,10}$ Furthermore, symptoms of insomnia and poor sleep quality are known to insist for a significant time period in many women after giving childbirth, with around $60 \%$ of mothers reporting recovery from insomnia symptoms at eight weeks postpartum and around $40 \%$ of mothers at two years postpartum. ${ }^{11}$

Apart from experiences of childbirth, previous studies have also reported a relationship between lifestyle habits, such as alcohol, smoking, exercise, and diet, and sleep quality. In fact, a correlation between excessive alcohol consumption and poor subjective sleep quality, reduced sleep duration, and increased sleep disturbances have been previously reported. ${ }^{12}$ Likewise, cigarette smokers are known to show poorer sleep quality than the general population. ${ }^{13}$ Last, in a study assessing the effect of a walking intervention on subjective sleep quality, a walking intervention significantly improved perceived sleep quality in both exercising and non-exercising participant groups. ${ }^{14}$ Despite reported associations between lifestyle habit and sleep, in addition to the fact that such factors are largely modifiable, no previous study has examined its potential effect on sleep quality in postpartum women. Therefore, the aim of this study was to investigate the association between recent experiences of childbirth and sleep quality in South Korean women and to additionally examine how lifestyle factors interplay in the stated relationship.

\section{Methods}

\section{Study Population and Data}

This study used data from the 2018 Korea Community Health Survey (KCHS), which is a study conducted annually by the Korea Centers for Disease Control and Prevention. The KCHS is the only community-based cross-sectional study that exists in Korea, in which the survey is conducted annually at 253 administrative sites. Information is collected through in-person (one-on-one) interviews using the computer-assisted personal interview (CAPI) method. The study population is drawn from multistage, stratified area probability samples of civilian, non-institutionalized households classified based on geographic region, age, and sex. As the final study population sample is extracted based on national survey data, samples are considered as a representative of the Korean population. $^{15}$

The 2018 KCHS data consisted of a total of 228,340 study participants. Women aged between 19 and 55 years were included as the study population as recent experience of childbirth was inquired only to this specific group in the $\mathrm{KCHS}$. Hence, 165,614 individuals not subject to inquiry on recent childbirth experience (males, ages 56 years or above, etc.) were excluded. A total of 21,018 individuals with missing values on the studied variables were also excluded, resulting in the final study population consisting of 41,708 individuals.

\section{Measures}

\section{Outcome Variable}

The outcome measure of this study was sleep quality, measured using the Korean version of the Pittsburgh sleep quality index (PSQI) questionnaire. The PSQI is a 19-item selfreported questionnaire that measures the quality and pattern of sleep over a one-month period. Specifically, the PSQI consists of 19 items that add up to 7 components, which are subjective sleep quality, sleep latency, sleep duration, sleep efficiency, sleep disturbances, use of sleep medication, and daytime dysfunction. Each component is scored into a scale between 0 and 3 and by adding the 7 components together, a general score measuring overall sleep quality can be obtained. The general score ranges between 0 and 21 scores of 6 or above commonly indicates poor sleep, as adopted in this study. The Korean version of the PSQI has been previously validated with high sensitivity and specificity. ${ }^{16,17}$ Furthermore, a cutoff point of 5 has also been validated in the Korean population. $^{18}$

\section{Recent Experience of Childbirth}

The interesting variable of this study was "recent experience of childbirth." Participants were inquired the following question: "Do you have experience giving birth (including normal and preterm birth) in the past year?" The available 
answers were a 'yes' or a "no." Based on this question, women with experience of childbirth in the past one year were categorized into the 'yes' category. Previous studies investigating the psychological effect of childbirth have targeted individuals who had delivered in the past one year. ${ }^{19}$ The one-year standard was also applied in research investigating depression and stress after childbirth in parents. ${ }^{20}$

In Korea, a paid maternity leave of 90 days (including at least 45 days postpartum) to women and a parental leave of one year to women and men is legally guaranteed. A total of $80 \%$ of average income for the first three months of parental leave and $50 \%$ of average income for the remaining nine months are paid. Hence, women with experience of giving birth may have been in their maternal or parental leave at the time of study.

\section{Covariates}

The covariates of this study were age (19 29, 30 39, $40 \sim 49$, or 50 55), education (middle school or below, high school, or below or university or above), income level (Q1 Q4), household composition (one, two, or three generation household), objectively measured body mass index [BMI (BMI $<18.5,18.5 \leq \mathrm{BMI}<25.0,25.0$ $\leq \mathrm{BMI}<50.0$ )], subjective health status (fair or poor), stress (no or yes), healthy lifestyle habit (no or yes), depressive symptoms (no or yes), job classification (whitecollar, blue-collar, pink-collar, or unemployed), marital status (married, divorced, widowed, or separated, or single), and region (urban or rural). Various sociodemographic variables were incorporated in the analysis as they may act as potential contributing factors in giving childbirth in women. Individuals were categorized into the "yes" healthy lifestyle habit group if they were current non-smokers, not high-risk alcohol users, and engaged in at least 30 minutes of walking or physical activity for over 4 days per week. Depressive symptoms were measured using the Patient Health Questionnaire (PHQ-9) as this tool has been widely used in different population-based studies. This study utilized the Korean version of the PHQ-9, which has been previously validated. ${ }^{21,22}$ Region was classified into urban or rural based on the participants' registered administrative district.

\section{Statistical Analysis}

The general characteristics of the study population were examined using the chi-square test to identify significant differences between groups. Multivariable logistic regression analysis was performed to investigate the association between recent experiences of childbirth and sleep quality while controlling for the potential confounding variables. Results were expressed as Odds Ratio (OR) and their 95\% Confidence Interval (95\% CI). Subgroup analysis was performed based on healthy lifestyle habit. All analyses were conducted using the SAS 9.4 (SAS Institute, Cary, NC, USA) software. P-values were two-sided and considered significant at $\mathrm{p}<0.05$.

\section{Ethical Approval}

The Korea Community Health Survey (KCHS) data are openly published. Participants' data were fully anonymized prior to release. Our study was excluded from the review list pursuant to Article 2.2 of the Enforcement Rule of Bioethics and Safety Act in Korea, since the data were exempted from IRB review. All procedures performed in studies involving human participants were in accordance with the ethical standards of the national research committee and with the 1964 Helsinki declaration and its later amendments or comparable ethical standards.

\section{Results}

Table 1 presents the general characteristics of the study population. Of a total of 41,708 individuals, 16,877 (40.5\%) participants expressed poor sleep quality. The percentage of individuals experiencing poor sleep quality was higher in women with a recent experience of childbirth $(48.4 \%)$ than those without $(40.0 \%)$. In terms of sociodemographic status, poor sleep quality was also more prevalent in individuals with fewer years of education, in lower income groups, in non-white collar jobs, and who have been separated. Regarding health, more participants in the "no" healthy lifestyle habit group reported poor sleep quality than those in the "yes" group. Poor sleep quality was also more commonly found in individuals with poor subjective health, stress, and depressive symptoms.

Table 2 shows the results of the association between recent experience of childbirth and poor sleep quality in women. Compared to individuals without a recent experience of childbirth, those with such an experience were more likely to experience poor sleep quality (OR 1.50, 95\% CI 1.34-1.68). Odds of showing poor sleep quality decreased in participants with a healthy lifestyle (OR 0.87 , 95\% CI 0.82-0.91).

The results of the subgroup analysis on the association between recent experience of childbirth and poor sleep quality by lifestyle habit can be found in Table 3. The 
Table I General Characteristics of the Study Population

\begin{tabular}{|c|c|c|c|c|c|c|}
\hline \multirow{3}{*}{$\begin{array}{l}\text { Variables } \\
\text { Recent experience of childbirth }\end{array}$} & \multirow{4}{*}{$\begin{array}{l}\text { Total } \\
39,234\end{array}$} & \multicolumn{4}{|c|}{ Poor Sleep Quality (PSQI > 5) } & \multirow[t]{2}{*}{ P-value } \\
\hline & & \multicolumn{2}{|c|}{ No } & \multicolumn{2}{|c|}{ Yes } & \\
\hline & & & & & & \\
\hline No & & 23,554 & $(60.0)$ & 15,680 & $(40.0)$ & $<0.0001$ \\
\hline Yes & 2474 & 1277 & $(51.6)$ & 1197 & $(48.4)$ & \\
\hline \multicolumn{7}{|l|}{ Age } \\
\hline $19 \sim 29$ & 8425 & $513 \mid$ & $(60.9)$ & 3294 & $(39.1)$ & $<0.0001$ \\
\hline $30 \sim 39$ & 10,296 & 6011 & $(58.4)$ & 4285 & $(4 I .6)$ & \\
\hline $40 \sim 49$ & 13,464 & 8307 & $(6 \mid .7)$ & 5157 & $(38.3)$ & \\
\hline $50 \sim 55$ & 9523 & 5382 & $(56.5)$ & $4|4|$ & $(43.5)$ & \\
\hline \multicolumn{7}{|l|}{ Education } \\
\hline Middle school or below & 1005 & 475 & $(47.3)$ & 530 & $(52.7)$ & $<0.0001$ \\
\hline High school & 20,320 & $\mathrm{II}, 774$ & $(57.9)$ & 8546 & $(42.1)$ & \\
\hline University or above & 20,383 & 12,582 & $(6 \mid .7)$ & 7801 & $(38.3)$ & \\
\hline \multicolumn{7}{|l|}{ Income } \\
\hline QI & 10,419 & 5699 & $(54.7)$ & 4720 & $(45.3)$ & $<0.0001$ \\
\hline Q2 & 7296 & 4258 & $(58.4)$ & 3038 & $(4 \mid .6)$ & \\
\hline Q3 & 13,353 & 8273 & $(62.0)$ & 5080 & $(38.0)$ & \\
\hline Q4 & 10,640 & 6601 & $(62.0)$ & 4039 & $(38.0)$ & \\
\hline \multicolumn{7}{|l|}{ Household composition } \\
\hline One generation household & 9701 & 5666 & $(58.4)$ & 4035 & $(4 I .6)$ & 0.0322 \\
\hline Two generation household & 28,713 & 17,204 & $(59.9)$ & 11,509 & $(40.1)$ & \\
\hline Three generation household & 3294 & $|96|$ & $(59.5)$ & 1333 & $(40.5)$ & \\
\hline \multicolumn{7}{|c|}{ Objectively measured body mass index } \\
\hline Underweight (BMI < I8.5) & 3050 & 1792 & $(58.7)$ & 1258 & $(4 \mid .3)$ & $<0.0001$ \\
\hline Normal $(I 8.5 \leq \mathrm{BMI}<25.0)$ & 29,307 & 17,828 & $(60.8)$ & 11,479 & $(39.2)$ & \\
\hline Obesity $(25.0 \leq \mathrm{BMI}<50.0)$ & 9351 & 5211 & $(55.7)$ & $4 \mid 40$ & $(44.3)$ & \\
\hline \multicolumn{7}{|l|}{ Subjective health status } \\
\hline Good & $|7,30|$ & 12,217 & $(70.6)$ & 5084 & $(29.4)$ & $<0.0001$ \\
\hline Poor & 24,407 & $12,6 \mid 4$ & $(5 \mid .7)$ & $\mathrm{II}, 793$ & $(48.3)$ & \\
\hline \multicolumn{7}{|l|}{ Stress } \\
\hline No & 30,193 & 20,029 & $(66.3)$ & 10,164 & $(33.7)$ & $<0.0001$ \\
\hline Yes & $11,5 \mid 5$ & 4802 & $(4 \mid .7)$ & 6713 & $(58.3)$ & \\
\hline \multicolumn{7}{|l|}{ Healthy lifestyle habit } \\
\hline No & 25,250 & 14,629 & $(57.9)$ & $|0,62|$ & $(42.1)$ & $<0.0001$ \\
\hline Yes & 16,458 & 10,202 & $(62.0)$ & 6256 & $(38.0)$ & \\
\hline \multicolumn{7}{|l|}{ Depressive symptoms } \\
\hline No & 40,290 & 24,692 & $(6 \mid .3)$ & 15,598 & $(38.7)$ & $<0.0001$ \\
\hline Yes & 1418 & 139 & $(9.8)$ & 1279 & $(90.2)$ & \\
\hline \multicolumn{7}{|l|}{ Job classification } \\
\hline White-collar worker & 13,125 & 8194 & $(62.4)$ & 4931 & $(37.6)$ & $<0.0001$ \\
\hline Pink-collar worker & 7853 & 4652 & $(59.2)$ & 3201 & $(40.8)$ & \\
\hline Blue-collar worker & 5515 & 3279 & $(59.5)$ & 2236 & $(40.5)$ & \\
\hline Unemployed & 15,215 & 8706 & $(57.2)$ & 6509 & $(42.8)$ & \\
\hline
\end{tabular}

(Continued) 
Table I (Continued).

\begin{tabular}{|c|c|c|c|c|c|c|}
\hline \multirow{3}{*}{$\begin{array}{l}\text { Variables } \\
\text { Marital status }\end{array}$} & \multirow[t]{2}{*}{ Total } & \multicolumn{4}{|c|}{ Poor Sleep Quality (PSQI > 5) } & \multirow[t]{2}{*}{ P-value } \\
\hline & & \multicolumn{2}{|c|}{ No } & \multicolumn{2}{|c|}{ Yes } & \\
\hline & & & & & & \\
\hline Married & 28,557 & 17,107 & $(59.9)$ & 11,450 & $(40.1)$ & $<0.0001$ \\
\hline Divorced, widowed, or separated & 3258 & 1655 & $(50.8)$ & 1603 & $(49.2)$ & \\
\hline Single & 9893 & 6069 & $(6 \mid .3)$ & 3824 & $(38.7)$ & \\
\hline \multicolumn{7}{|l|}{ Region } \\
\hline Urban & 28,743 & 16,919 & $(58.9)$ & 11,824 & $(4 I . I)$ & $<0.0001$ \\
\hline Rural & 12,965 & 7912 & $(6 I .0)$ & 5053 & $(39.0)$ & \\
\hline Total & 41,708 & 24,831 & $(59.5)$ & 16,877 & $(40.5)$ & \\
\hline
\end{tabular}

trends of the main findings were generally maintained as individuals with a recent experience of childbirth had higher likelihoods of experiencing poor sleep quality. At the same time, the extent of such difference was reduced in individuals with a healthy lifestyle (OR 1.29, 95\% CI 1.07-1.56) than those without (OR 1.63, 95\% CI 1.41-1.88 ), inferring that lifestyle habits may partially moderate the relationship between childbirth experience and poor sleep quality.

\section{Discussion}

The findings of this study present that a recent experience of childbirth is associated with an increased likelihood of undergoing poor sleep quality using a large, nationally representative data on South Korean women. Moreover, as the degree of this relationship found was reduced in individuals with a healthy lifestyle (not smoking, not engaging in high-risk alcohol use, and walking or exercising for at least 30 minutes per day, 5 days a week), the results suggest the potential effects of lifestyle habit in postnatal women. The results are in accordance with many existing studies which have reported prevalent poor sleep quality and insufficient sleep in individuals during and after pregnancy. ${ }^{23}$ Women generally report highest levels of exhaustion during the first three postpartum months, with around $40 \%$ of women reporting sleep disturbances at two years postpartum. ${ }^{11,24}$ As for studies conducted in Asia, most have focused on investigating sleep quality and duration in pregnant women. For instance, a previous Chinese cross-sectional study has presented that poor quality of sleep occurs commonly during pregnancy. Likewise, a study conducted in South Korea has shown that sleep quality tends to gradually worsen as women reach their later months of pregnancy. ${ }^{25,26}$ Hence, sleep disturbances can be seen as frequently expressed concerns among postpartum women. ${ }^{27}$

The association between childbirth experience and sleep quality may be explained by the fact that sleep quality in women is related to alterations in hormonal levels, including fluctuations that may occur due to the stress of bearing different roles in the transitional stages instantly after childbirth. ${ }^{28}$ In fact, women may be distressed as they integrate the new role of parenthood into their pre-existing responsibilities following the addition of a new family member. ${ }^{10,29}$ Demands of a new role, parenthood, may decrease sleep quality resulting from changes in duties and increased strains and worries. Poor postpartum sleep may also involve children's dependence on nocturnal feedings and other necessary caretaking activities. ${ }^{23}$ Additionally, physical pain following delivery may also be an influencing factor, particularly as cesarean section women report more frequent sleep disturbances than women who gave natural childbirth. ${ }^{13,30}$

This study also investigated the relationship between recent childbirth and sleep quality according to lifestyle habit. Components of the "healthy lifestyle habit" variable, which are current smoking status, high-risk alcohol behavior engagement status, and regular walking or exercise status, are known risk factors for poor sleep quality. ${ }^{12-14}$ The main findings on childbirth experience and sleep quality were generally maintained regardless of having a healthy lifestyle, although the degree of difference between postnatal women and their counterparts was slightly reduced in participants with a healthy lifestyle. This is noteworthy as it infers that in addition to women 
Table 2 Results of the Multivariable Logistic Regression Analysis of the Association Between Recent Experience of Childbirth and Poor Sleep Quality

\begin{tabular}{|c|c|c|c|c|}
\hline \multirow[t]{2}{*}{ Variables } & & \multicolumn{3}{|c|}{ Poor Sleep Quality (PSQI > 5) } \\
\hline & Adjusted-OR* & \multicolumn{3}{|c|}{$95 \% \mathrm{Cl}$} \\
\hline \multicolumn{5}{|c|}{ Recent experience of childbirth } \\
\hline No & 1.00 & & & \\
\hline Yes & 1.50 & 1.34 & - & 1.68 \\
\hline \multicolumn{5}{|l|}{ Age } \\
\hline $19 \sim 29$ & 1.00 & & & \\
\hline $30 \sim 39$ & 1.06 & 0.96 & - & 1.16 \\
\hline $40 \sim 49$ & 0.99 & 0.89 & - & 1.09 \\
\hline $50 \sim 59$ & 1.13 & 1.01 & - & 1.26 \\
\hline \multicolumn{5}{|l|}{ Education } \\
\hline Middle school or below & 1.00 & & & \\
\hline High school & 0.70 & 0.58 & - & 0.86 \\
\hline University or above & 0.63 & 0.52 & - & 0.77 \\
\hline \multicolumn{5}{|l|}{ Income } \\
\hline QI & 1.00 & & & \\
\hline Q2 & 0.92 & 0.84 & - & 1.00 \\
\hline Q3 & 0.90 & 0.84 & - & 0.99 \\
\hline Q4 & 0.91 & 0.83 & - & 1.05 \\
\hline \multicolumn{5}{|l|}{ Household composition } \\
\hline One generation household & 1.00 & & & \\
\hline Two generation household & 0.98 & 0.92 & - & 1.05 \\
\hline Three generation household & 1.02 & 1.01 & - & 1.15 \\
\hline \multicolumn{5}{|c|}{ Objectively measured body mass index } \\
\hline Normal $(\mid 8.5 \leq \mathrm{BMI}<25.0)$ & 1.00 & & & \\
\hline Underweight (BMI < 18.5) & 1.01 & 0.91 & - & 1.12 \\
\hline Obesity $(25.0 \leq \mathrm{BMI}<50.0)$ & 1.08 & 1.01 & - & 1.15 \\
\hline \multicolumn{5}{|l|}{ Subjective health status } \\
\hline Good & 1.00 & & & \\
\hline Poor & 1.91 & 1.81 & - & 2.02 \\
\hline \multicolumn{5}{|l|}{ Stress } \\
\hline No & 1.00 & & & \\
\hline Yes & 2.26 & 2.13 & - & 2.40 \\
\hline \multicolumn{5}{|l|}{ Healthy lifestyle habit } \\
\hline No & 1.00 & & & \\
\hline Yes & 0.87 & 0.82 & - & 0.91 \\
\hline \multicolumn{5}{|l|}{ Depressive symptoms } \\
\hline No & 1.00 & & & \\
\hline Yes & 8.40 & 6.70 & - & 10.53 \\
\hline \multicolumn{5}{|l|}{ Job classification } \\
\hline White-collar worker & 1.00 & & & \\
\hline Pink-collar worker & 1.02 & 0.94 & - & 1.11 \\
\hline Blue-collar worker & 1.02 & 0.92 & - & 1.12 \\
\hline Unemployed & I.II & 1.04 & - & 1.19 \\
\hline
\end{tabular}

(Continued) 
Table 2 (Continued).

\begin{tabular}{|c|c|c|c|c|}
\hline \multirow[t]{2}{*}{ Variables } & & \multicolumn{3}{|c|}{ Poor Sleep Quality (PSQI > 5) } \\
\hline & Adjusted-OR* & \multicolumn{3}{|c|}{$95 \% \mathrm{Cl}$} \\
\hline \multicolumn{5}{|l|}{ Marital status } \\
\hline Married & 1.00 & & & \\
\hline Divorced, widowed, or separated & 1.22 & 1.10 & - & 1.36 \\
\hline Single & 0.99 & 0.90 & - & 1.08 \\
\hline \multicolumn{5}{|l|}{ Region } \\
\hline Urban & 1.00 & & & \\
\hline Rural & 0.97 & 0.91 & - & 1.04 \\
\hline
\end{tabular}

Note: *Adjusted for age, education, income, household composition, objectively measured body mass index, subjective health status, stress, depressive symptoms, job classification, marital status, and region.

Table 3 The Results of Subgroup Analysis of the Association Between Recent Experience of Childbirth and Poor Sleep Quality by Healthy Lifestyle Habit

\begin{tabular}{|c|c|c|c|c|c|}
\hline \multirow{2}{*}{\multicolumn{2}{|c|}{ Variables }} & \multirow[b]{2}{*}{ Adjusted-OR* } & \multicolumn{3}{|c|}{ Poor Sleep Quality (PSQI > 5) } \\
\hline & & & \multicolumn{3}{|c|}{$95 \% \mathrm{Cl}$} \\
\hline $\begin{array}{l}\text { Healthy lifestyle habit } \\
\text { No }\end{array}$ & $\begin{array}{l}\text { Recent experience of childbirth } \\
\text { No } \\
\text { Yes }\end{array}$ & $\begin{array}{l}1.00 \\
1.63\end{array}$ & 1.41 & - & 1.88 \\
\hline Yes & $\begin{array}{l}\text { No } \\
\text { Yes }\end{array}$ & $\begin{array}{l}1.00 \\
1.29\end{array}$ & 1.07 & - & 1.56 \\
\hline
\end{tabular}

Note: *Adjusted for age, education, income, household composition, objectively measured body mass index, subjective health status, stress, depressive symptoms, job classification, marital status, and region.

with recent childbirth experience being more likely to experience poor sleep quality, such likelihoods may escalate in those not carrying out healthy behavior practice. Adequately monitoring these individuals may hence be important, especially considering that Asian countries report the most rapid and serious increases in sleep disorders. ${ }^{7}$ The potential benefits of not smoking, disengaging in high-risk alcohol behavior, and walking or exercising on a regular basis in improving sleep quality should be highlighted based on the protective effects of healthy practice behavior shown in postpartum women.

The findings are noteworthy because total fertility rates (TFRs) have remained particularly low in many East Asian countries, including Korea. ${ }^{31}$ A combination of noticeable improvements in women's status, such as higher education attainment and employment rates, and high domestic gender inequality has been cited as the main contributing factor. ${ }^{32}$ This is because Korea is an example in which rapid changes in the society have taken place as a result of its fast-economic growth unseen in most other countries. ${ }^{33}$
Hence, the demands of the new role of parenthood accompanying childbirth may be particularly stressed in Korea. Although a paid maternity leave and a partially paid parental leave are legally guaranteed, many women often express difficulty in combining work and family. Furthermore, little nighttime support is known to negatively influence sleep quality in postpartum women. ${ }^{34}$ Hence, women may be at a particular risk of experiencing poor sleep quality after childbirth, inferring the importance of reporting and monitoring this indicator.

This study was not without its limitations. First, the findings do not necessarily infer a causal association as this study was cross-sectional in design. Second, the specific timing of childbirth (eg, 1 month postpartum, etc.) could not be considered. Third, the possibility of residual confounding cannot be completely ruled out. For instance, information on snoring, nighttime breastfeeding, and mother parity was not measured in the data used. Information on sleep disorders was also unavailable and hence, individuals with a previous diagnosis could not be 
excluded nor this variable considered as a covariate. Information on the participants' current professional status, including whether they were on maternity, could also not be considered. Fourth, lifestyle habits were measured based on smoking, alcohol drinking, and physical activity but the frequency of women with childbirth experience in the past year currently smoking and drinking was low, at around $2 \%$ and $5 \%$. Last, sleep quality was using the Korean version of the PSQI, which has been proven for its validity and reliability. Although this is a comprehensive scale, scoring above the cut-off does not necessarily imply a clinical diagnosis. However, despite the limitations stated above, this study offers new insights by using a community-based design and included a large, nationally representative sample of women. The findings add evidence that recent experience in childbirth is associated with poor sleep quality, inferring the need to monitor and implement previously assessed interventions that may enhance sleep in postpartum women. ${ }^{35}$

\section{Conclusions}

Recent experience of childbirth was associated with higher likelihoods of poor sleep quality in women. The degree of risks found was reduced in individuals with healthy practice behavior, referring to those who do not smoke, do not participate in high-risk alcohol behavior, and walks or exercises for at least 30 minutes per day, 5 days or more per week. The findings of this study infer the need to monitor and address sleep-related disturbances commonly reported among postpartum women.

\section{Abbreviations}

PSQI, Pittsburgh sleep quality index; PHQ-9, patient health questionnaire-9; BMI, body mass index.

\section{Data Sharing Statement}

Data will be made available on request. The dataset is available on the Korea Community Health Survey website (https://chs.cdc.go.kr/chs/rdr/rdrInfoProcessMain.do).

\section{Funding}

The present study received no financial support.

\section{Disclosure}

The authors declare no competing interests.

\section{References}

1. Orr W. International Encyclopedia of the Social \& Behavioral Sciences: Sleep and Health. Elsevier Ltd; 2001.

2. Okano K, Kaczmarzyk JR, Dave N, Gabrieli JDE, Grossman JC. Sleep quality, duration, and consistency are associated with better academic performance in college students. NPJ Sci Learn. 2019;4:16. doi:10.1038/s41539-019-0055-Z

3. Lee JE, Ju YJ, Park EC, Lee SY. Effect of poor sleep quality on subjective cognitive decline (SCD) or SCD-related functional difficulties: results from 220,000 nationwide general populations without dementia. $J$ Affect Disord. 2020;260:32-37. doi:10.1016/j. jad.2019.08.082

4. Harvey AG, Stinson K, Whitaker KL, Moskovitz D, Virk H. The subjective meaning of sleep quality: a comparison of individuals with and without insomnia. Sleep. 2008;31(3):383-393. doi:10.1093/sleep/ 31.3.383

5. Pilz LK, Keller LK, Lenssen D, Roenneberg T. Time to rethink sleep quality: PSQI scores reflect sleep quality on workdays. Sleep. 2018;41(5):5. doi:10.1093/sleep/zsy029

6. Buysse DJ, Reynolds CF 3rd, Monk TH, Berman SR, Kupfer DJ. The Pittsburgh Sleep Quality Index: a new instrument for psychiatric practice and research. Psychiatry Res. 1989;28(2):193-213. doi:10.1016/0165-1781(89)90047-4

7. Cherasse Y. Overview of sleep and sleep medicine in Asian countries. Sleep Biol Rhythms. 2011;9(s1):84-89. doi:10.1111/j.14798425.2010.00468.x

8. Coo S, Milgrom J, Trinder J. Mood and objective and subjective measures of sleep during late pregnancy and the postpartum period. Behav Sleep Med. 2014;12(4):317-330. doi:10.1080/ 15402002.2013.801348

9. Insana SP, Montgomery-Downs HE. Sleep and sleepiness among first-time postpartum parents: a field-and laboratory-based multimethod assessment. Dev Psychobiol. 2013;55(4):361-372. doi: $10.1002 /$ dev. 21040

10. Hunter LP, Rychnovsky JD, Yount SM. A selective review of maternal sleep characteristics in the postpartum period. J Obstet Gynecol Neonatal Nurs. 2009;38(1):60-68. doi:10.1111/j.15526909.2008.00309.x

11. Sivertsen B, Hysing M, Dørheim SK, Eberhard-Gran M. Trajectories of maternal sleep problems before and after childbirth: a longitudinal population-based study. BMC Pregnancy Childbirth. 2015;15(1):129. doi:10.1186/s12884-015-0577-1

12. Park SY, Oh MK, Lee BS, et al. The Effects of Alcohol on Quality of Sleep. Korean J Fam Med. 2015;36(6):294-299. doi:10.4082/ kjfm.2015.36.6.294

13. Purani H, Friedrichsen S, Allen AM. Sleep quality in cigarette smokers: associations with smoking-related outcomes and exercise. Addict Behav. 2019;90:71-76. doi:10.1016/j. addbeh.2018.10.023

14. Hori H, Ikenouchi-Sugita A, Yoshimura R, Nakamura J. Does subjective sleep quality improve by a walking intervention? A real-world study in a Japanese workplace. BMJ Open. 2016;6(10):e011055. doi:10.1136/bmjopen-2016-011055

15. Kang Y, Ko Y, Kim Y, et al. Korea community health survey data profiles. Osong Public Health Res Perspect. 2015;6(3):211-217. doi:10.1016/j.phrp.2015.05.003

16. Lee SY, Ju YJ, Lee JE, et al. Factors associated with poor sleep quality in the Korean general population: providing information from the Korean version of the Pittsburgh Sleep Quality Index. $J$ Affect Disord. 2020;271:49-58. doi:10.1016/j.jad.2020.03.069

17. Sohn SI, Kim DH, Lee MY, Cho YW. The reliability and validity of the Korean version of the Pittsburgh Sleep Quality Index. Sleep Breathing. 2012;16(3):803-812. doi:10.1007/s11325-011-0579-9 
18. Choi H, Kim S, Kim B, Kim I. Psychometric properties of the Korean versions of three sleep evaluation questionnaires. Clin Nurs Res. 2015;24(5):526-538. doi:10.1177/1054773814549827

19. Javadifar N, Majlesi F, Nikbakht A, Nedjat S, Montazeri A. Journey to motherhood in the first year after child birth. J Family Reprod Health. 2016;10(3):146-153.

20. Johansson M, Benderix Y, Svensson I. Mothers' and fathers' lived experiences of postpartum depression and parental stress after childbirth: a qualitative study. Int J Qual Stud Health Well Being. 2020;15 (1):1722564. doi:10.1080/17482631.2020.1722564

21. Han C, Jo SA, Kwak J-H, et al. Validation of the Patient Health Questionnaire-9 Korean version in the elderly population: the Ansan Geriatric study. Compr Psychiatry. 2008;49(2):218-223. doi:10.1016/ j.comppsych.2007.08.006

22. Choi HS, Choi JH, Park KH, et al. Standardization of the Korean Version of Patient Health Questionnaire-9 as a screening instrument for major depressive disorder. J Korean Acad Family Med. 2007;28 (2):114-119.

23. Richter D, Kramer MD, Tang NKY, Montgomery-Downs HE, Lemola S. Long-term effects of pregnancy and childbirth on sleep satisfaction and duration of first-time and experienced mothers and fathers. Sleep. 2019;42:4. doi:10.1093/sleep/zsz015

24. Kennedy HP, Gardiner A, Gay C, Lee KA. Negotiating sleep: a qualitative study of new mothers. $J$ Perinat Neonatal Nurs. 2007;21(2):114-122. doi:10.1097/01.JPN.0000270628.51122.1d

25. Xu X, Liu D, Zhang Z, Sharma M, Zhao Y. Sleep duration and quality in pregnant women: a cross-sectional survey in China. Int J Environ Res Public Health. 2017;14(7):7. doi:10.3390/ ijerph 14070817

26. Kim KT, Cho YW, Bae JG. Quality of sleep and quality of life measured monthly in pregnant women in South Korea. Sleep Breath. 2020;24(3):1219-1222. doi:10.1007/s11325-020-02041-0
27. Goyal D, Gay CL, Lee KA. Patterns of sleep disruption and depressive symptoms in new mothers. J Perinat Neonatal Nurs. 2007;21 (2):123-129. doi:10.1097/01.JPN.0000270629.58746.96

28. Lee KA, Baker FC, Newton KM, Ancoli-Israel S. The Influence of reproductive status and age on women's sleep. J Women's Health. 2008;17(7):1209-1214. doi:10.1089/jwh.2007.0562

29. Hung HM, Chen CH. Sleep quality in postpartum women: exploring correlation with childbirth experience and household work. J Nurs Res. 2014;22(1):20-27. doi:10.1097/jnr.0000000000000015

30. Lee SY, Lee KA. Early postpartum sleep and fatigue for mothers after cesarean delivery compared with vaginal delivery: an exploratory study. J Perinat Neonatal Nurs. 2007;21(2):109-113. doi:10.1097/ 01.JPN.0000270627.73993.b0

31. Population Reference Bureau Staff. World Population Data Sheet, Each Year. Washington D.C: Population Reference Bureau; 2014.

32. Kim E. Division of domestic labour and lowest-low fertility in South Korea. Demogr Res. 2017;37:743-768. doi:10.4054/ DemRes.2017.37.24

33. Hwang J. Housewife,"gold miss," and equal: the evolution of educated women's role in Asia and the US. J Popul Econ. 2016;29 (2):529-570. doi:10.1007/s00148-015-0571-y

34. Posmontier B. Sleep quality in women with and without postpartum depression. J Obstet Gynecol Neonatal Nurs. 2008;37(6):722-737. doi:10.1111/j.1552-6909.2008.00298.x

35. Lee KA, Gay CL, Alsten CR. Sleep enhancement training for pregnant women. Obstet Gynecol. 2016;128(5):964-971. doi:10.1097/ AOG.0000000000001654

\section{Publish your work in this journal}

Nature and Science of Sleep is an international, peer-reviewed, open access journal covering all aspects of sleep science and sleep medicine, including the neurophysiology and functions of sleep, the genetics of sleep, sleep and society, biological rhythms, dreaming, sleep disorders and therapy, and strategies to optimize healthy sleep.
The manuscript management system is completely online and includes a very quick and fair peer-review system, which is all easy to use. Visit http://www.dovepress.com/testimonials.php to read real quotes from published authors. 